IUD occurred within 1 week of the test are taken into account, however, the incidence is reduced to $0,4 \%$. This figure is further reduced to $0,3 \%$ when cases in which the fetus was alive on admission are also excluded almost the same incidence $(0,4 \%)$ was found by Evertson et $a l^{20}$ When it is taken into account that disasters such as abruptio placentae, amniotic fluid infection or haemorrhage due to placenta praevia cannot be predicted, the real proportion of false-positive test results is very small. Other clinical conditions in which an OCT should be interpreted with caution are diabetes, fetal haemolytic disease, and pre-eclampsia suddenly increasing in severity.

I wish to thank Dr C. de W. Vivier, Superintendent of Tygerberg Hospital, for permission to publish. This study was supported by the South African Medical Research Council.

\section{REFERENCES}

1. Huddleston, J. F. and Freeman, R. K. in Bolognese, R. J. and Schwartz, R. H. eds (1977): Perinatal Medicine. Baltimore: Williams \& Wilkins.
2. Baskett, T. F. and Sandy, E. A. (1977): Brit. J. Obstet. Gynaec., 84, 39

3. Idem (1975): Amer. J.. Obs*et. Gynec., 123, 106.

4. Van Coeverden de Groot, H. A. (1979): S. Afr. med. J., 55, 823.

5. Naeye, R. L., Tafari, N. and Marboe, C. C. (1979): Acta obstet. gynec. scand., $\mathbf{5 8}, 37$.

6. Freeman, R. K. (1975): Amer. J. Obstet. Gynec., 121, 481.

7. Odendaal, H. J. and Sandenbergh, H. A. (1977): S. Afr. med. J.,

52, 473. Manseau, P., Vaquier, $J$.

Modanlou, H. D. Freeman, R. K., Ortiz, O. et al. (1977): Obstet. Modanlou, H., Free

and Gynec, 49, 1977.

Kubli, F., Ruttgers,

11. Seski, J. and Compton, A. A. (1976): Amer. J. Obstet. Gynec., 125, 276

12. Lee, C. G., Di Loreto, P. C. and Logrand, B. (1976): Obstet. and Gynec., 48, 19.

13. McCranie, W. M. and Niebyl, J. (1977): Ibid., 49, 241.

14. Farahani, G., Vasudeva, K., Petrie, R. et al. (1976): Ibid., 47, 159.

15. Egley, C. C. and Suzuki, K. (1977): Ibid., 50, 54.

16. Gal, D., Neuhoff, S., Lilling, M. I. et al. (1979): Amer. J. Obstet.

17. Lorenz, R. P. and Pagano, J. S. (1978): Ibid., 130, 232.

18. Salerno, N. J. and Kay, T. R. (1978): Ibid., 130, 849.

19. Klapholz, H. (1975): J. reprod. Med., 15, 169.

20. Evertson, L. R., Gauthier, R. J. and Collea, J. V. (1978): Obstet. and Gynec., 51. 671.

\title{
Uterine Contraction Patterns in Patients with Severe Abruptio Placentae
}

\author{
H. J. ODENDAAL
}

\section{SUMMARY}

Uterine contractions were monitored in 54 patients in whom severe abruptio placentae had caused intra-uterine death of the fetus. The frequency at the beginning of monitoring ranged from 2 to 14 contractions in 10 minutes, with a mean of 8,4 . Only 4 patients had 4 or fewer contractions in the first 10 minutes of monitoring. No change in contraction frequency was observed during the course of labour. A high frequency of contractions before or during labour is highly suggestive of severe abruptio placentae.

S. Afr. med. J., 57, 908 (1980).

\footnotetext{
Department of Obstetrics and Gynaecology, University of Stellenbosch and Tygerberg Hospital, Parowvallei, CP

H. J. ODENDAAL, M.B. CH.B., F.C.o.G. (S.A.), M.R.c.o.g., M.MED. (O. \& G.) (Present address: Department of Obstetrics and Gynaecology, University of the Orange Free State, Bloemfontein)
}

Date received: 31 October 1979.
An increase in the frequency of uterine contractions occurs in patients with abruptio placentae. ${ }^{1}$ Although frequent contractions are rarely present during normal labour $(\mathbf{H}$. J. Vandeput - unpublished data), it is still uncertain how often they occur in patients with severe abruptio placentae, since uterine atonia has also been described in this condition. ${ }^{2}$ This study was therefore undertaken to investigate uterine activity in patients with severe abruptio placentae.

\section{PATIENTS AND METHODS}

Patients in whom the diagnosis of abruptio placentae could be made on definite clinical grounds and in whom no fetal heart beat could be heard with a Doppler apparatus were selected for the study. After admission to the obstetric special care unit, the patient's clinical condition was assessed and the necessary resuscitation was performed. A vaginal examination was done to assess the condition of the cervix and to rupture the membranes. An open-tipped plastic catheter was introduced into the uterine cavity for direct recording of intra-uterine pressures. When the cervix was not sufficiently dilated for insertion of the 
catheter, uterine contractions were monitored by the external method until the internal method could be used. The uterus was not stimulated unless the contractions had been recorded for at least 10 minutes. All recordings were carried out using a Hewlett-Packard model 8020A cardiotocograph at a paper speed of $1 \mathrm{~cm} / \mathrm{min}$.

The progress of labour was assessed by cervical dilatation as measured at vaginal examination every 4 hours. When there was no progress for a period of at least 8 hours, a caesarean section was performed. Abdominal delivery was also performed when oliguria persisted after the hypovolaemia, as judged by a central venous pressure line, had been corrected. After delivery the duration of the first stage of labour was recorded - the time of admission to the special care unit was regarded as the beginning of the first stage, and in patients who had caesarean section, the beginning of the operation was regarded as the end of the first stage. After delivery the diagnosis of abruptio placentae was confirmed by the presence of retroplacental blood clots.

Each patient's tocograph was then examined, and the contraction frequency in the first 10 -minute period was assessed. The tocographs were divided into 2-hour periods, working backwards from the end of the recording to the beginning. The mean 10-minute contraction frequency for each 2-hour period in every recording was calculated. In some patients a clear recording was not obtained and it was impossible to count the contractions accurately. They were therefore excluded from the series. Lastly, patients who had had vaginal deliveries were compared with those who had had caesarean sections in respect of duration of labour, birth weight and initial contraction frequency the clinical and haematological data have been reported previously. ${ }^{3}$

\section{RESULTS}

Sixty-three patients with abruptio placentae which had caused intra-uterine death of the fetus were studied. Nine patients were excluded because of poor registration of the uterine contractions. Patients' ages varied from 16 to 46 years, with a mean of 26,6 years. Twenty patients were nulliparous and 9 patients had had 1 or 2 previous pregnancies. There were 40 normal deliveries, 11 caesarean sections, 3 breech deliveries and 1 vacuum extraction, and there was 1 twin pregnancy.

The initial frequency of contractions ranged from 2 to 14 in 10 minutes, with a mean of 8,4 . Only 4 patients had 4 or fewer contractions in the first 10 minutes of monitoring. Uterine contractions were recorded for longer than 14 hours in 5 patients, but in 49 patients only the last 2 hours of labour were monitored. Oxytocin was given to 27 patients. In the period 14-16 hours before delivery the mean contraction frequency was 5 in 10 minutes, but it later stabilized to between 6 and 8,5 in 10 minutes (Table I). The contraction frequency for individual patients also remained constant during the course of labour (Fig. 1).

The duration of the first stage of labour in patients who had had a caesarean section ranged from 3 to 16 hours, with a mean of 8 hours 45 minutes (SD 3 hours 36 minutes). In patients who delivered normally the duration of the

\section{TABLE I. CONTRACTION FREQUENCY OF THE UTERUS DURING LABOUR}

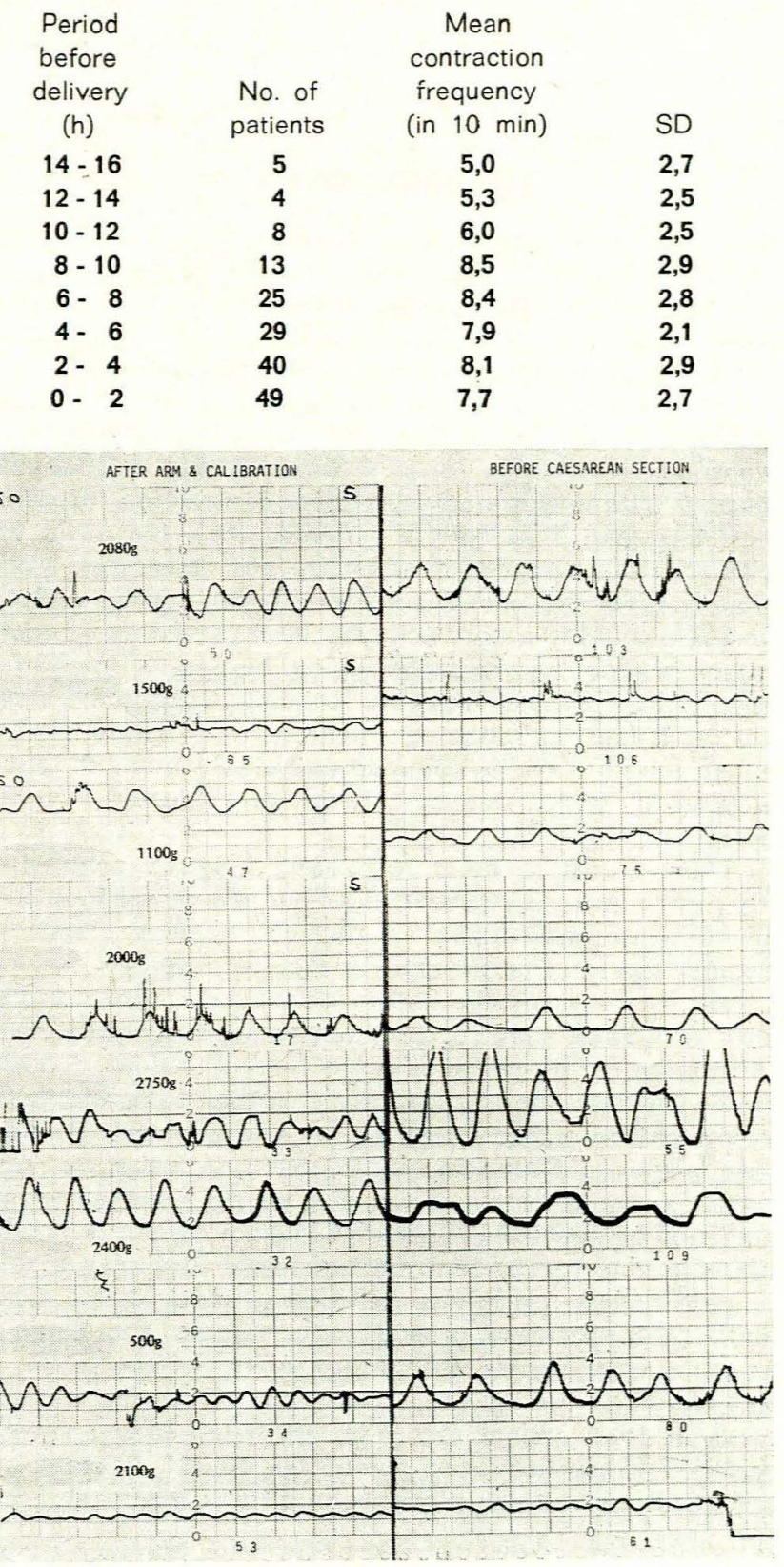

Fig. 1. The frequency of uterine contractions in individual patients immediately after the commencement of monitoring and before delivery.

first stage ranged from 2,5 hours to 26 hours 35 minutes, with a mean of 9 hours 58 minutes (SD 5 hours 28 minutes). The difference in the duration of the first stage of labour in the two groups was not statistically significant ( $t=0,67 ; P>0,05)$.

Three infants weighed less than $500 \mathrm{~g}$ and 3 more than $3001 \mathrm{~g}$; birth weights in the majority were between 1501 and $2000 \mathrm{~g}$. Only 1 of the infants delivered by caesarean 
section weighed more than $2500 \mathrm{~g}$ and and only 5 weighed more than $2000 \mathrm{~g}$. The mean birth weight for infants delivered by caesarean section was $1714 \mathrm{~g}$ (SD 806), which is slightly less than the $1824 \mathrm{~g}$ (SD 728) of infants delivered vaginally. The difference in birth weight is not significant $(t=1,90 ; P<0,05)$.

\section{DISCUSSION}

For intra-uterine death to occur, at least two-thirds of the placenta has to be separated from the uterine wall. ${ }^{4}$ All the patients included in the series could be regarded as cases of severe or grade III abruptio placentae, because intra-uterine death of the fetus had occurred in all.

The frequency of uterine contractions in severe abruptio placentae is unique - in normal labour the uterus rarely contracts more than 3 or 4 times during a 10-minute period. During this study the initial contraction frequency was less than 5 in only 4 patients, while the mean was 8,4 . These contraction frequencies were measured immediately after the commencement of monitoring, and the increase could therefore not have been caused by oxytocin, which was not administered during the first 10 minutes of monitoring. The contraction frequency did not change during labour, although contractions were slightly less frequent long before the commencement of labour; the small number of patients studied in this period could have led to this observation.

There seems to be a correlation between contraction frequency and the outcome of labour, the initial frequency being significantly higher in patients in whom caesarean section was later performed for lack of progress.

The aetiology of this almost diagnostic contraction pattern is unknown, but several factors may contribute to it. Abruption of the placenta could cause a sudden decrease in the progesterone-blocking effect on the uterus and therefore result in a high-frequency or low-amplitude contraction pattern. A decrease in progesterone levels was seen when placental function was destroyed by intra-amniotic injection of hypertonic saline..$^{5}$ A sudden release of prostaglandins due to decidual damage could also play a role, since it has been demonstrated that stripping of the membranes can increase prostaglandin release and cause a change in the contraction pattern of the uterus. ${ }^{6}$ Cobo et $a l .^{*}$ described the increased frequency of uterine contractions in 1965 and at that time attributed it to a 'severe functional disturbance on the uterine fibers'. Eskes et al. ${ }^{8}$ recorded intra-uterine pressures in a few cases of abruptio placentae, describing a high frequency of contractions as well as a higher tonus, and postulated that this incomplete relaxation of the uterus could have been due to a sympathetic influence. This group of workers also described elevated intra-uterine pressures and a high frequency of contractions in patients with polyhydramnios. ${ }^{9}$ During drainage of amniotic fluid the pressure during contractions as well as the frequency of contractions decreased. Distension of the uterus, as is the case in severe abruptio placentae, could have the same effect as polyhydramnios. However, in this series no correlation was found between the size of the retroplacental clot and the contraction frequency.

In this series it is unlikely that cephalopelvic disproportion necessitated the caesarean sections, because these infant's birth weights did not differ from those of infants delivered vaginally and in any case the birth weights were low (only 1 infant weighed more than $2500 \mathrm{~g}$ ).

Although the cause for the increased contraction frequency in abruptio placentae remains debatable, it serves as an important diagnostic tool, since contractions can easily be recorded by external methods. If contractions are found to be frequent before or during labour, abruptio placentae should seriously be considered in the differential diagnosis.

The contraction pattern is probably also a cause of the high incidence of intra-uterine deaths in patients with abruptio placentae, since the frequent contractions prevent adequate blood flow to the intervillous space. Patients with abruptio placentae should therefore be delivered as soon as possible, unless the fetal heart rate can be monitored adequately and facilities are available for immediate caesarean section in the case of fetal distress.

I wish to thank the registrárs of the Department of Obstetrics and Gynaecology, Tygerberg Hospital, for their help with this study, which was supported by the South African Medical Research Council.

\section{REFERENCES}

1. Odendaal, H. J. (1976): S. Afr. med. J., 50, 2129.

3. Odendaal, H. J., Brink, S. and Steytler, J. G. (1978): S. Afr. med. J., 54, 476.

4. Page, E. W., King, E. B. and Merrill, J. A. (1954): Obstet. and Gynec., 3, 358 .

5. Csapo, A. I., Herczeg, J., Pulkkinen, M. et al. (1976): Amer. J. Obstet. Gynec., 124, 1.

6. Mitchell, M. D., Flint, A. P. F., Bibby, J. et al. (1977): Brit. med. J., *

7. Cobo, E., Quintero, C. A., Strada, G. et al. (1965): Amer. J. Obstet. Gynec., 93, 1151.

8. Eskes, T., Seelen, J. and Stolte, L. (1967): Ned. T. Verlosk., 67, 74

9. Idem (1967): Ibid., 67, 251 . 